\title{
Effects of Fluoride of Antarctic Krill (Euphausia superba) Meal on Accumulation and Weight of Mice
}

\author{
Yue Yuan ${ }^{1,2}$, Haifeng Yu ${ }^{3}$, Youqiong $\mathrm{Cai}^{1}$, Hai Chi ${ }^{1, *}$ \\ ${ }^{1}$ East China Sea Fisheries Research Institute, Chinese Academy of Fishery Sciences, Shanghai, China \\ ${ }^{2}$ Liaoning Province Dalian Ocean Fishery Group of Corp, Dalian, China \\ ${ }^{3}$ Anshan Institute for Food and Drug Control, Anshan, China
}

Email address:

xiaoyuan8000@sina.com(Yuan Yue),18941210412@163.com(Haifeng Yu),caiyouqiong@163.com(Youqiong Cai), andychihai@126.com(Hai Chi)

${ }^{*}$ Corresponding author

\section{To cite this article:}

Yue Yuan, Haifeng Yu, Youqiong Cai, Hai Chi. Effects of Fluoride of Antarctic Krill (Euphausia superba) Meal on Accumulation and Weight of Mice. International Journal of Nutrition and Food Sciences. Vol. 8 No. 2, 2019, pp. 36-39. doi: 10.11648/j.ijnfs.20190802.12

Received: April 8, 2019; Accepted: July 2, 2019; Published: July 19, 2019

\begin{abstract}
Antarctic krill (Euphausia superba) possesses rich nutritional value, large fishing capacity and potentials for processing and utilization. However, the development and utilization of Antarctic krill is impeded by its high fluorine contents. In this study, Antarctic krill meal and sodium fluoride solution $(300 \mathrm{mg} / \mathrm{L})$ were selected as the study objects to feeding mice, and the effects of fluoride on accumulation and weight gained in small intestine, blood, liver, and kidney femur of mice were investigated. The results showed that the contents of small intestine, blood, liver and kidney in the group of the mice fed with Antarctic krill and sodium fluoride remained less than $1 \mathrm{mg} / \mathrm{kg}$, which was slightly higher than that of the blank control group $(p<0.05)$. The fluoride contents in the femur of mice fed with Antarctic krill meal and sodium fluoride solution were ten times higher than that of the blank control group, indicating that the fluorine in Antarctic krill meal was likely different from the chemical fluorine in sodium fluoride. No signification difference on accumulation of fluoride was found in the small intestine, blood, liver and kidney of mice, but fluorine from Antarctic krill meal and sodium fluoride was obviously deposited in the femur of mice. On the other hands, the weight gained rate of mice in the sodium fluoride group was $3.22 \%$, and that of mice in Antarctic krill meal group was $7.81 \%$, both of that were significantly lower than that in the blank group (12.87\%). The results showed that the fluorine in Antarctic krill meal inhibited the growth of mice, but its specific absorption, metabolism and transformation process in the body still needed to be further studied.
\end{abstract}

Keywords: Antarctic Krill Meal, Fluoride, Absorption Metabolism, Weight Gained

\section{Introduction}

Krill are in the family of pelagic marine planktonic crustaceans that widely distributed throughout the world's oceans [1]. Antarctic krill (Euphausia superba) is one of the most commercial targeted one, and is known as the most abundant species [2-3]. Antarctic krill also plays key roles in sustaining the food chain in the marine ecosystem in Antarctic Ocean [2]. It has reported that the estimated amounts of Antarctic krill are approximately $6.5-10.0 \times 10^{8} \mathrm{t}$, the large-scale commercial fishing and potential applications on its utilization as good resource have drawn attentions.

The biology and potential values of Antarctic krill have been recently reviewed and documented [4-6]. Antarctic krill possesses high contents of protein with relative low fat compared to other fishery products. Its unsaturated fatty acid with a high portion of EPA and DHA indicated that Antarctic krill presents an excellent protein resource. Besides that, mineral substances from Antarctic krill were suitable for human assimilation and utilization [1].

High level of fluoride in Antarctic krill is always a concern for its utilization and development. Generally, the contents of fluoride in Antarctic krill range at $500-2000 \mathrm{mg} / \mathrm{kg}$ in the whole body, $5-600 \mathrm{mg} / \mathrm{kg}$ in muscle and $2000-4000 \mathrm{mg} / \mathrm{kg}$ in cuticle, respectively [7-9]. Such high level of fluoride contents in Antarctic krill may cause mottled teeth, renal 
disease, diabetes mellitus and allergies [10]. However, toxic effects caused by directly having Antarctic krill are not known. It has been a controversy case when the fluoride is induced to human being. WHO recommended that the daily intake of fluoride for adult is about 2-4 mg, and FDA is in the agreement with take less than $100 \mathrm{mg} / \mathrm{kg}$ of fluoride (sodium fluoride) daily [11]. In the recent study, scientific report dedicated to analyze the relationships between the forms of fluoride and their toxicity in Antarctic krill. The results showed that most of the fluoride in Antarctic krill is in inorganic form, implying the having limited amount of Antarctic krill is likely to be no harmful [12]. It is important to analyze the accumulation and metabolize of Antarctic krill in advanced.

In this study, we investigated on the accumulation and metabolize of fluoride in Antarctic krill on mice by using Antarctic krill meal and sodium fluoride. Hopefully to provide safety amounts of fluoride from Antarctic krill by analyzing the accumulation levels of different organs of mice.

\section{Materials and Method}

\subsection{Materials}

30 female Kunming mice (weight about 15-21 g) were purchased from Fudan University (Shanghai, China). Antarctic krill was captured from FAO48.1, and immediately processed on the factorial ship. The Antarctic krill meal after processed was stored and delivered to Shanghai under the condition of $-18^{\circ} \mathrm{C}$.

\subsection{Preparation of Fluorine Standard Solution}

Approximately $0.22 \mathrm{~g}$ of sodium fluoride was dried at $105^{\circ} \mathrm{C}$ for $4 \mathrm{~h}$, and subsequently put at constant volume at $100 \mathrm{~mL}$. The standard solution (solution A) was ten-fold series dilution to 10000 times and stored at $4{ }^{\circ} \mathrm{C}$ for further investigation. In addition, $10.37 \mathrm{~g}$ of Antarctic krill meal was constantly volume at $100 \mathrm{~mL}$.

\subsection{Determination of Fluoride Content}

Fluoride content was detected by using electrode method followed the description of GB/T5009.18-2003 [13]. Samples from organs and thighbone were homogenized and incinerated respectively before the determination of fluoride content.

\subsection{Animal Experiments}

Mice were grouped into 3 different cages, each cage possessed 10 mice. Each mouse weighted and starved for 12 $\mathrm{h}$ before starting feeding with sodium fluoride ( $1 \mathrm{~mL}$ per day) and Antarctic krill meal $(1 \mathrm{~mL}$ of Antarctic krill meal suspension per day). The mice fed with $1 \mathrm{~mL}$ of deionized water were marked as control group. All the mice were fed for 7 days continuously, and executed by cervical spine dislocation as described by Jung et al. [14]. Small intestine, blood, liver, kidney and thighbone were selected and stored at $-18^{\circ} \mathrm{C}$ for further investigation.

\subsection{Statistics Analysis}

SPSS 12.0 was used for data analysis. The determined fluoride contents were expressed by mean \pm standard deviation $(\mathrm{n}=10)$. T-test was used for statistical comparison.

\section{Results and Discussion}

\subsection{Fluoride Contents in Antarctic Krill Meal}

Fluoride contents in Antarctic krill meal were detected by using the electrode method and the values of fluoride contents in Antarctic krill meal was calculated according to the standard curve (figure 1). In our study, the fluoride contents of Antarctic krill meal was $2894 \pm 30 \mathrm{mg} / \mathrm{kg}$. The results showed in agreement with Shen et al. [15]. Soevik and Braekken also determined the fluoride contents of Antarctic krill individually and every part[16]. The results showed that the distribution of fluoride in Antarctic krill varied. The fluoride in head of Antarctic krill showed high concentration $(4260 \mathrm{mg} / \mathrm{kg})$, the fluoride in shell and muscle were 3300 and $570 \mathrm{mg} / \mathrm{kg}$, respectively.

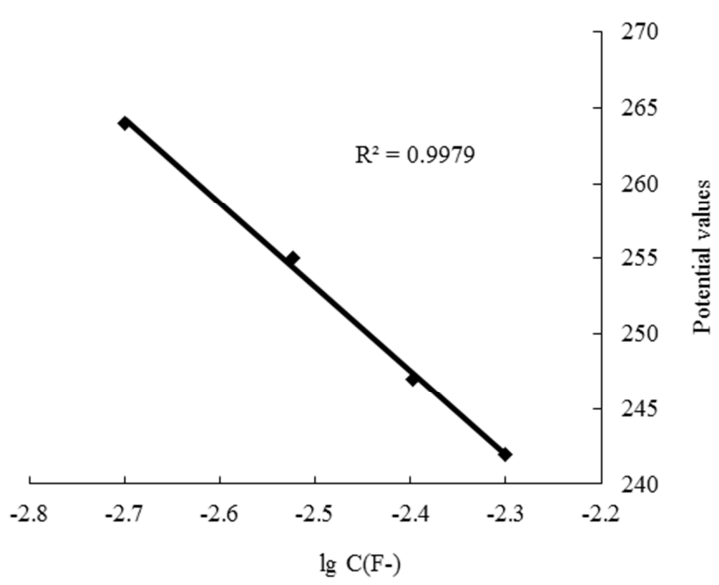

Figure 1. Standard curve of fluoride concentration.

\subsection{Absorption and Metabolism of Fluorine in Antarctic Krill}

The fluoride content was calculated by substituting the potential values of mice serum, liver, kidney and small intestine into the standard curve equation. The results are shown in Table 1.

Table 1. Sodium fluoride and Antarctic krill meal fluorine absorption and metabolism in small intestine, blood, liver, kidney and thighbone of mice (mg/kg).

\begin{tabular}{llllll}
\hline Samples & Small intestine & Blood & Liver & Kidney & Thighbone \\
\hline Control & $0.18 \pm 0.07$ & $0.45 \pm 0.03$ & $0.45 \pm 0.08$ & $0.32 \pm 0.06$ & $484.92 \pm 60.42$ \\
NaF & $0.19 \pm 0.04$ & $0.76 \pm 0.09$ & $0.80 \pm 0.07$ & $0.67 \pm 0.06$ & $4603.96 \pm 834.77$ \\
Antarctic krill & $0.18 \pm 0.05$ & $0.50 \pm 0.04$ & $0.42 \pm 0.09$ & $0.51 \pm 0.14$ \\
\hline
\end{tabular}


The small intestine is the main place for food digestion and absorption. The substances in the body are decomposed into small molecules that can be absorbed through the digestion of the small intestine. Inorganic fluoride is absorbed by the body through diffusion in the gastric wall and small intestine. The fluoride content in the small intestine of all three groups was at the same level, and no significant difference $(p>0.05)$ was found. The results showed that no fluoride accumulation in small intestine of mice was obviously found from both sodium fluoride and Antarctic krill meal after 7 days feeding.

Fluorine normally is absorbed by the body and transported to various tissues and organs through blood. Table 1 demonstrated that the fluoride content in blood from sodium fluoride group was higher than other groups, indicating the fluoride is unable to be completely discharged by the mice. The fluoride content in blood from Antarctic krill meal was slightly higher than the control group. However, no significant difference was found $(p>0.05)$. The similar results from Ringe were observed from 24-hours feeding of fats with Antarctic krill meal [17]. Those results indicated that fluoride in Antarctic krill may not be absorbed or easily discharged, so that the fluoride in blood maintained normal level.

No significant different was found from the fluoride content in liver, suggesting that fluoride in all groups did not effectively accumulate. The fluoride content in kidney of mice in sodium fluoride group and Antarctic krill powder group was higher than that in control group. This may be related to the fact that fluoride in the blood of both groups did not reach the level of the control group. No significant difference in fluoride content between Antarctic krill meal group and control group, but to sodium fluoride group. The results indicated that the metabolism rate of fluoride in Antarctic krill meal was faster than that in sodium fluoride group.

The results showed that high fluoride content in thighbone of mice was found in the sodium fluoride group and the Antarctic krill meal group indicating that fluoride from both groups had obvious accumulation effect. The same results were found by Yoshitomi et al. who fed yellow tail with Antarctic krill meal instead of fish meal. They found high residues of fluoride content in the vertebrae [18]. Slight difference from fluoride content of thighbone was found between sodium fluoride and Antarctic krill meal group. It may be due to the different chemical forms of fluoride in Antarctic krill meal and the simple chemical fluoride in sodium fluoride, the process of absorption and metabolism was more complex, and was less easily absorbed by bone tissue than that in sodium fluoride group. The specific reasons need to be further studied on the form of fluorine in Antarctic krill meal and the process of absorption and metabolism in vivo.

\subsection{Effect of Fluoride in Antarctic Krill Meal on Weight in Mice}

The effect of fluoride on weight gained of mice is shown in Table 2. The increasing weight of mice treated with sodium fluoride and Antarctic krill were $0.56 \mathrm{~g}$ and $1.46 \mathrm{~g}$, respectively. Compared to the control group, the increasing weight of other two groups showed significant difference. The results may be caused by the deposition of fluoride in tissues and bone, resulting in the slow growth or decreasing weight gained rate of mice. In addition, significant difference in weight gained between Antarctic krill meal and sodium fluoride group was found, indicating that such concentration of fluoride may inhibit the growth of mice stronger than that of Antarctic krill meal under the same amount of fluoride.

Table 2. Weight gained of mice faded with sodium fluoride and Antarctic krill meal.

\begin{tabular}{lllll}
\hline Samples & $\begin{array}{l}\text { Initial } \\
\text { weight/g }\end{array}$ & End weight/g & $\boldsymbol{\Delta g}$ & $\begin{array}{l}\text { Increasing } \\
\text { rate/\% }\end{array}$ \\
\hline Control & $15.77 \pm 0.97$ & $17.80 \pm 1.01$ & 2.03 & 12.87 \\
$\mathrm{NaF}$ & $17.40 \pm 0.26$ & $17.97 \pm 0.55$ & 0.56 & 3.22 \\
Antarctic krill & $18.70 \pm 1.08$ & $20.16 \pm 0.67$ & 1.46 & 7.81 \\
\hline
\end{tabular}

\section{Conclusion}

To explore the concentration and accumulation of fluoride from Antarctic krill meal, the systematic study was conducted. The results demonstrated that the fluoride in Antarctic krill per se was up to $2894 \pm 30 \mathrm{mg} / \mathrm{kg}$. Beside of that, Fluoride accumulation was evaluated in our study. Fluoride in blood of mice fed with sodium fluoride and Antarctic krill meal were relative high compared to control group. Fluoride accumulated in bone tissue, which led to the weight gained of mice in both groups was significantly lower than control group. The results showed that the accumulation of fluoride in bone tissue of Antarctic krill meal likely affected the growth of mice. Therefore, it is suggested that adult intake of Antarctic krill (60 kg) should not exceed 300 $\mathrm{mg} / \mathrm{kg}$ per day. In addition, there was no accumulation of fluoride in the small intestine of mice in all groups, suggesting the chemical forms of fluorine in Antarctic krill meal may different from those of pure fluoride ion in sodium fluoride. The forms of fluorine in Antarctic krill meal and its absorption and transformation in vivo remain to be further studied.

\section{Acknowledgements}

This work was financially supported by the National Key R\&D Program of China (No. 2017YFC1600706).

\section{References}

[1] Chi H., Li XY, Yang XS. Processing status and utilization strategies of Antarctic krill (Euphausia superba) in China [J]. World Journal of Fish and Marine Sciences, 2013, 5 (3): 275-281.

[2] Tou J C, Jaczynski J, Chen Y C. Krill for human consumption: nutritional value and potential health benefits $[\mathrm{J}]$. Nutrition Reviews, 2007, 65 (2): 63-77. 
[3] Nicol S, Endo Y. Krill fisheries of the world [R]. FAO Fisheries Technical Paper, 1997, 367: 9-16.

[4] Nicol S, Foster J. Recent trends in the fishery for Antarctic krill [J]. Aquatic Living Resources, 2003, 16: 42-45.

[5] Chi H, Li XY, Yang XS. Research progress on process and utlization of Antarctic krill [J]. Natural Product Reseach and Development, 2010, 22: 283-287.

[6] Sayed Z. South ocean ecology. The biomass perspective. El-sayed, Cambrige University Press. 1997, UK.

[7] Zhang H, Cheng X, Zhu B. Biogeochemistry research of fluoride in Antarctic krill [J]. Antarctic Research, 1993, 4: 55-61.

[8] Xie CL, Kim HS, Shim KB. Organic acid extraction of proteins with low fluoride level from Antarctic krill [J]. Fisheries and Aquatic Sciences, 2012, 15: 203-207.

[9] Sands M, Nicol S, McMinn A. Fluoride in Antarctic marine crustaceans [J]. Marine Biology, 1998, 132: 591-598.

[10] Jung HR, Kim M., Seo YS, et al. Decreasing effect of fluoride content in Antarctic krill (Euphausia superba) by chemical treatments $[\mathrm{J}]$. International Journal of Food Science and Technology, 2013, 48: 1252-1259.

[11] FDA. Whole fish protein concentrate. Code of Federal Regulations. 2012, 21CFR172.385.
[12] Pan JM, Zhang HS, Liu XY. The fluiride enrichment mechanics of Antarctic krill I. The fluoride chemical formation [J]. Acta Oceanologica Sinica, 2002, 22 (2): 58-64.

[13] Ministry of Health of the People's Republic of China, National Standardization Administration Committee of China. Determination of Fluorine in Foods [S]. GB/T5009. 18-2003.

[14] Jung HR, Kim MA, Seo YS, et al. Decreasing effect of fluoride content in Antarctic krill (Euphausia superba) by chemical treatments $[\mathrm{J}]$. International Journal of Food Science and Technology, 2013, 48: 1252-1259.

[15] Shen XS, Li YL, Zhang HY, et al. Distribution and relationship of fluoride and mineral elements in Antarctic krill [J]. Modern Food Science and Technology, 2013, 9 (29): 2279-2282.

[16] Soevik T, Braekkan O R. Fluoride in Antarctic Krill (Euphausia superba) and Atlantic Krill [J]. Journal of the Fisheries Research Board of Canada, 1979, 36 (11): 1414-1416.

[17] Ringe JD, Meunier PJ. What is the future for fluoride in the treatment of osteoporosis? [J]. Osteoporosis International, 1995, 5: 71-74.

[18] Yoshitomi B, Aoki M, Oshima S. Effect of total replacement of dietary fish meal by low fluoride krill (Euphausia superba) meal on growth performance of rainbow trout (Oncorhynchus mykiss) in fresh water [J]. Aquaculture, 2007, 266 (1): 219-225. 